\title{
La perspectiva estructural de la justicia y los migrantes
}

The structural perspective of justice and migrants

\section{Francisco Blanco Brotons}

Instituto de Filosofía del CSIC, Madrid franciscojose.blanco@cchs.csic.es

Orcid: 0000-0001-8805-9637

DOI: http://dx.doi.org/10.15366/bp.2020.23.006 Bajo Palabra. II Época. No23. Pgs: 163-186 
Resumen

Rawls definió la justicia como una virtud de la estructura básica. Las características mediante las que interpretó a esta, sin embargo, impusieron a la teoría de la justicia de graves limitaciones en cuanto a su capacidad para afrontar los nuevos problemas a los que nos enfrenta nuestro mundo en globalización. Uno de ellos es el de las injusticias que sufre el creciente número de migrantes internacionales, sobre al que la teoría de Rawls guarda silencio. En este artículo se expondrá, en primer lugar, un enfoque estructural alternativo al rawlsiano, para, en segundo lugar, evaluar su potencial crítico aplicándolo al caso de las injusticias que sufren los migrantes. El objetivo de este texto suministrar un enfoque teórico más adecuado desde el que abordar uno de los desafíos más acuciantes de nuestro mundo.

Palabras clave:justicia global, estructura social, injusticia estructural, globalización, migrantes.

\section{Abstract}

Rawls defined justice as a virtue of the basic structure. The characteristics by which he interpreted it, however, imposed severe limitations on the theory of justice in terms of its ability to confront the new problems we face in our globalizing world. One of them is that of the injustices suffered by the growing number of international migrants, about which Rawls' theory is silent. In this article an alternative structural approach will be presented and, in order to evaluate its critical potential, we will apply it to the case of the injustices suffered by migrants. The aim of this text is to provide a more adequate theoretical approach from which to address one of the most pressing challenges in our world.

Keywords: global justice, social structure, structural injustice, globalization, migrants. 


\section{Introducción}

TEORÍA DE LA JUSTICIA, obra fundamental de John Rawls, contiene una idea fundamental: "el objeto primario de la justicia es la estructura básica de la sociedad" (Rawls 2014: 20). La justicia sirve para evaluar el sistema público de reglas que rigen nuestros sistemas de cooperación. El objeto inmediato de atención de la justicia son las estructuras sociales por su carácter fundamentador de las situaciones de necesidad. En este texto, se denominará a esta perspectiva "concepción estructural".

La igualdad moral de las personas, desde esta perspectiva, no significa que todas las personas tengan que recibir el mismo trato en tanto que personas simpliciter, sino en tanto que se encuentran sujetas a un mismo sistema de cooperación, que no debe perjudicar sistemáticamente a ninguna en beneficio de otra. En este sentido, la justicia es una cuestión relacional, atiende a las personas en tanto que sus relaciones están mediadas a través de estructuras sociales.

La forma en que Rawls concibe la estructura básica tiene tres características destacables:

(1) Su teoría se caracteriza por adoptar una perspectiva distributiva, de modo que lo que la estructura básica hace es distribuir algo (Rawls 2014: 22).

(2) La estructura básica está formada por instituciones públicas cuyas normas están claramente definidas y delimitadas, y son conocidas por todos los que participan en ella (id.: 62-64).

(3) Rawls cree que la más amplia y significativa relación institucional que las personas establecen es con las estructuras de su propio Estado. Fuera de la cooperación que se da entre ciudadanos dentro de un Estado, no hay relaciones de justicia (Rawls 2001).

Para algunos autores, sin embargo, esta concepción estructural no es aceptable, pues parece postergar, o incluso desterrar fuera del ámbito de la justicia, las necesidades más urgentes de las personas reales. Según ellos, la extrema pobreza de la que adolece una importante fracción de la humanidad reclama, más bien, que la justicia 
ponga su foco en la satisfacción inmediata de las necesidades básicas de todos y no en la reforma de estructuras básicas (Arcos Ramírez 2008; Caney 2006).

Para hacer frente a esta objeción a la concepción estructural, el objetivo que aquí se plantea consiste en ampliar y profundizar la concepción de la justicia propuesta por Rawls, siguiendo a pensadores como Nancy Fraser, Rainer Forst o Iris Marion Young. La concepción estructural es una perspectiva imprescindible e irrenunciable para abordar la injusticia. Sin embargo, es necesaria una revisión y ampliación de la forma en la que Rawls la entendía si queremos responder de un modo más adecuado y comprehensivo a las injusticias que surgen en un marco global. Con este objetivo, este artículo se organiza en tres partes. En la primera se revisará la concepción rawlsiana de estructura básica. En las otras dos se pondrá a prueba esta perspectiva mediante su aplicación a un colectivo frecuentemente olvidado por las teorías liberales: los migrantes. En la segunda, se propondrá un esquema analítico sobre cómo tratar desde esta concepción el caso de las injusticias que sufren los migrantes. En la última parte se pondrá a prueba este esquema en un ejemplo ficticio inspirado en casos reales.

\section{Replanteamiento de la concepción estructural}

Nancy Fraser, Rainer Forst e Iris Marion Young, entre otros, transforman la concepción de la estructura básica mantenida por Rawls, al complementar la primera de las tres características que señalamos al comienzo, pues rechazan que la justicia deba adoptar exclusivamente una perspectiva distributiva; al complejizar la segunda característica señalada, ampliando el ámbito estructural que constituye el objeto de la justicia; y rechazando la tercera, pues insisten en que las instituciones significativas trascienden el marco del Estado, insistiendo en los deberes globales de justicia. A continuación, cada una de estas diferencias con la teoría de Rawls será abordada en subapartados independientes.

\subsection{La justicia desde una perspectiva multidimensional}

Según Rainer Forst (2014) e Iris Marion Young (2000), plantear la justicia desde una perspectiva exclusivamente distributiva excluye a priori la consideración de importantes injusticias. Esta orientación oculta aspectos esenciales de la justicia. En especial, oscurece la dominación y la opresión y sirve para legitimar la despolitización de los sistemas de cooperación. Así, por ejemplo, al fijarse meramente en 
cantidades de bienes recibidas aleja la atención de los procesos de producción. La estructura básica es una construcción política intersubjetiva y debe ser ante todo examinada en relación a los procesos de su justificación. Junto al aspecto distributivo de la justicia, es necesario considerar también su aspecto político.

Además de esta dimensión política, Fraser enfatiza la necesidad de incorporar la dimensión de reconocimiento. Hay injusticias para las que el paradigma distributivo no tiene una explicación adecuada, como el androcentrismo, el etnocentrismo, el heterocentrismo o en general cualquier estructura básica que imponga una relación institucionalizada de subordinación de estatus, que representa al otro -a todo aquel que no pertenece a la propia comunidad, sea como fuera ésta concebida- como inferior, impidiendo su participación igual en las interacciones sociales (Fraser 2006: 36).

Las demandas de justicia que pueden elevarse hacia la estructura básica se diversifican. Ésta no sólo se podrá enjuiciar según el modo en que distribuye bienes socialmente valiosos, sino también según el modo en que se institucionalizan patrones de valoración cultural que benefician a algunos grupos mientras desfavorecen a otros -dimensión de reconocimiento- y según el modo en que institucionalizan formas de dominación en las que se excluye a algunas personas de la posibilidad de determinar las reglas del sistema cooperativo al que están sometidos -dimensión política-.

\subsection{Concepción compleja de la estructura social}

De ACUERDo CON RaWls, para entender plenamente una concepción de justicia, entre otras cosas, su idea de estructura básica y la forma de enjuiciarla, "tenemos que hacer explícita la concepción de cooperación social de la cual se deriva" (Rawls 2014: 23). La concepción de cooperación social presupuesta en su teoría, se mantiene en los márgenes de la tradición contractualista. Se basa en la idea de un acuerdo original entre personas libres y racionales interesadas en promover sus propios intereses, mediante el que instauran una estructura básica claramente determinada y limitada a un espacio político concebido como el ámbito sobre el que pueden alcanzarse acuerdos unánimes entre todos los ciudadanos razonables, por oposición a un espacio privado no político dejado al arbitrio de cada cual.

Según Iris Marion Young (2011: 61-131), esta concepción de Rawls no refleja adecuadamente la complejidad de las múltiples relaciones institucionales en las que nos encontramos inmersos. Aunque Young está de acuerdo con Rawls en que el objeto de la justicia son las estructuras sociales, no el comportamiento de cada indi- 
viduo, ello no le impide reconocer al mismo tiempo la importancia de las acciones de los individuos en la existencia y el sostenimiento de la injusticia estructural. En muchos casos, para hablar de la injusticia estructural tendremos que atender a los hábitos de las personas y a sus acciones y disolver la rígida separación liberal entre lo público y lo privado, lo personal y lo político. Al fin y al cabo, nuestras normas y hábitos personales también están pública y políticamente conformados. Según Young, Rawls piensa de forma equivocada en la estructura y su error estriba en intentar identificar una parte de la sociedad más fundamental que el resto. Dicha autora considera, por el contrario, que "las estructuras sociales no forman parte de la sociedad, sino que se constatan o comprenden cierto modo de contemplar a toda la sociedad que ve pautas en las relaciones y en las posiciones que ocupan entre ellos" (Young 2011: 85). La perspectiva estructural es algo que asumimos cuando intentamos contemplar la convergencia de las acciones de conjuntos de individuos con un gran número de instituciones. Los juicios normativos sobre la estructura constituyen un punto de vista diferente a los juicios sobre las interacciones individuales. Los primeros suponen un punto de vista mucho más amplio, los segundos consideran cuestiones más directas. Que una persona no trate con respeto a otra es algo moralmente incorrecto, pero no es una injusticia. La injusticia aparece al mirar detrás de esta interacción particular y encontrarnos, por ejemplo, que se fundamenta sobre algún prejuicio sistemático y socialmente reforzado, es decir, patrones estructurales de comportamiento. Todas las interacciones relacionadas con una situación de injusticia pueden describirse desde estas dos perspectivas irreductibles.

En base a estos argumentos, la estructura básica se amplía. En primer lugar, en su contenido, pues esta ya no es una parte, sino un modo de contemplar toda la sociedad. En segundo lugar, en los procesos que implica, ya no limitados a los procesos formales de instituciones públicas claramente delimitadas, sino constituidos por un modo de ver todas las interacciones y procesos sociales. Por esta razón, resulta más conveniente hablar de estructura social en lugar de usar la expresión estructura básica, que parece hacer referencia a alguna parte delimitada.

\subsection{Rechazo de la limitación nacional de la estructura social}

EN EL DERECHO DE GENTES, Rawls desarrolla su visión de un sistema global de "pueblos", esto es, de sociedades estatalmente constituidas cerradas y autosuficientes. Los principios de justicia se aplicarían tan sólo al interior de cada uno de estos "pueblos", para regular las relaciones entre los miembros de cada una de estas sociedades y sus instituciones públicas. Según este autor, las personas sólo están 
sometidas de un modo relevante a la estructura básica de sus respectivos "pueblos", de modo que las únicas causas de su posible explotación o dominación deben buscarse en ella. Por todo ello, si alguna persona sufre injusticias, sólo puede reclamar legítimamente a las instituciones del "pueblo" al que pertenece. Esta concepción encaja con la perspectiva teórica conocida como "nacionalismo metodológico" (Sager 2016).

Contra esta perspectiva se alega que es aún presa del imaginario westfaliano, imaginario que, con los amplios procesos de la globalización, ya no constituye una descripción realista y útil de lo que acontece en nuestro mundo (Benhabib 2005: 61-96; Fraser 2008: 31-39). Resulta muy difícil negar hoy en día los profundos efectos que las regulaciones internacionales, las organizaciones supranacionales o los agentes económicos y sociales trasnacionales tienen en las vidas de todos los habitantes del planeta, así como trazar una línea divisoria que deje a un lado las afectaciones causales, las coacciones y los esquemas cooperativos que resultan significativos y a otro lado los que no lo son. Los diversos autores que aquí examinamos -Young, Fraser, Forst- defienden que, si de hecho las personas se encuentran sometidas a normas y procesos institucionales trasnacionales que producen injusticia, deben estar legitimadas para dirigirles reivindicaciones exactamente igual que a sus instituciones estatales, pues no es la pertenencia a un Estado concreto lo que legitima sus reclamaciones, sino su sometimiento a una estructura social responsable de sus injusticias y que hoy va más allá de los Estados-nación particulares (Young 2011: 116). Es más, Fraser interpreta el mantenimiento de los marcos estatales para la delimitación de las confrontaciones sobre la justicia como "la injusticia que define la era de la globalización". Esta forma de injusticia, que esta autora denomina "des-enmarque", surge

"cuando las fronteras de la comunidad se trazan de manera que alguien queda injustamente excluido en absoluto de la posibilidad de participar en las confrontaciones sobre justicia que le competen (...) $\mathrm{Al}$ instituir de un solo golpe a miembros y no miembros, esta decisión excluye efectivamente a estos últimos del universo de los que tienen derecho a ser tenidos en cuenta” (Fraser 2008: 45).

Con el fin de superar esta injusticia, Fraser propone que "todos aquellos que están sujetos a una estructura de gobernación determinada están en posición moral de ser sujetos de justicia en relación con dicha estructura" (id.: 65). Frente a los marcos monolíticos del enfoque westfaliano o frente a los que defienden un marco único cosmopolita, el resultado de buscar el correcto enmarque de cualquier injusticia será probablemente un conjunto de marcos múltiples correspondientes a los múltiples "quienes". Cada situación de injusticia no sólo estaría atravesada por las 
tres dimensiones sustantivas de la distribución, el reconocimiento y la representación, sino por múltiples marcos de pertenencia situados a distintos niveles: local, nacional, trasnacional, etc., en los que se ubican las diversas estructuras sociales causantes de la injusticia. Una misma persona está sometida a diversas "estructuras de gobernación" que pueden condicionar diferencialmente su situación, y una situación de injusticia puede igualmente responder a diferentes "marcos", todos los cuales deben ser analizados para luchar contra ella.

\section{El marco de análisis}

LAS INJUSTICIAS QUE SUFREN LAS PERSONAS, de acuerdo con la perspectiva estructural, deben ser abordadas examinando las estructuras sociales, los sistemas de reglas y recursos, que condicionan sus relaciones sociales. Los migrantes son un caso interesante, pues nos seńala lo que podría interpretarse como una limitación de esta perspectiva, pues si estos mediante su migración, como afirma Blake, están intentando "convertirse en sujetos" de una nueva estructura institucional diferente a la que se encuentran sometidos, quedarían a priori fuera de su marco de análisis (Blake 2014: 523). Según esta perspectiva, la justicia por definición sirve para evaluar las relaciones que se dan entre agentes sometidos a un mismo sistema institucional. No habría relaciones de justicia entre agentes que no estén vinculados mediante ninguna estructura social, y cualquier supuesto derecho de las personas a establecer nuevas relaciones a su antojo con otras personas no forma parte de su lenguaje o modo de abordar la cuestión de la justicia.

Esta es sin duda una característica importante de la forma de abordar la injusticia desde la perspectiva estructural, pero, como se argumentará, ni deja fuera a los migrantes ni constituye una carencia crítica. En nuestro actual mundo en globalización esta característica no es en verdad ninguna limitación, sino un criterio de diferenciación de estructuras, ámbitos y tipos de reivindicaciones: es un método eficaz para analizar y clarificar situaciones en sí muy complejas que deben tratarse de formas específicas. Encontrarse sometido a las estructuras de un mismo Estado, un caso de relaciones institucionales entre otros, impone relaciones de justicia específicas que no se tendrán con los que no se encuentran sometidas a ellas, y esto no tiene por qué infringir el igual valor moral de estos (D. Miller 2016: 20-37; R. W. Miller 1998: 207-210; Risse 2016: 445-447; Sangiovanni 2013). En la actualidad se dan múltiples relaciones institucionales, algunas globales o que traspasan el ámbito de cada Estado individual, que también deben ser evaluadas desde la perspectiva de la justicia. 
Pero se puede dar un paso más. Incluso si se aceptase que las relaciones relevantes desde el punto de vista de la justicia se limitan a las impuestas por los Estados, la concepción estructural tendría aún mucho que decir en relación con los migrantes. Es equivocado presuponer que los Estados receptores son agentes inocentes y sin responsabilidad ante los flujos migratorios de personas que pretenden traspasar sus fronteras, flujos que supuestamente estarían basados en cálculos individualistas que los migrantes realizan en base a sus propios intereses por comparación de su situación en sus países de origen y los beneficios esperados por residir en los de destino (Blake 2014; D. Miller 2008; Risse 2016). Los países de acogida, que necesitan a los migrantes por múltiples razones, regulan activamente los flujos migratorios e implementan diversos programas de cooperación con países emisores, canales de acceso y figuras jurídicas para introducir personas nuevas en su estructura cooperativa. Las comunidades políticas y sus estructuras sociales se expanden así más allá del territorio delimitado por sus fronteras y del conjunto de agentes a los que formalmente se les reconoce algún estatus de pertenencia. Ya no resulta apropiado concebir al Estado como un contenedor que mantiene al interior de sus fronteras territoriales todas las relaciones sociales que resultan por él estructuradas. Si esto es así, entonces Blake describía de forma inadecuada la realidad al decir que lo que buscan los migrantes es establecer a su antojo relaciones con unos Estados que les son ajenos, pues ellos ya se encuentran, y por iniciativa de los países receptores, relacionados con estos de varias formas. Desde la perspectiva estructural será necesario examinar si estas relaciones les hacen sufrir explotación, dominación o subordinación (Fraser 2008: 126-130). Este examen habrá de desarrollarse en torno al menos de tres tipos de cuestiones interrelacionadas: las diferentes dimensiones de las injusticias, el marco de análisis en el que situarlas y el momento en el que se ubican dentro del proceso temporal de la migración.

El primer tipo de cuestiones versa sobre las diversas formas de injusticias que son generadas por la estructura social. Las de tipo distributivo, como se expuso en el primer apartado, se complementan y refuerzan mediante las injusticias de reconocimiento y dominación. Es posible que las injusticias que padecen muchos de los migrantes sean en gran medida de tipo distributivo, pero no por ello las otras dos dimensiones - la de reconocimiento y la política - deben ser desatendidas, pues probablemente estas resulten fundamentales para comprender los modos como las injusticias de distribución ocurren y se mantienen, además de que sin duda existen migraciones que no son principalmente económicas. Nuestra hipótesis de partida es que en cada caso concreto se encuentran presentes estas tres dimensiones, condicionándose mutuamente, aunque alguna de ellas pudiera resultar preponderante. Se pretende adoptar, de este modo, el enfoque de la interseccionalidad. Esta forma 
de plantear la injusticia intenta evitar algunas de las simplificaciones que habitualmente se encuentran en los discursos sobre las migraciones, como por ejemplo la distinción entre migración económica y política (Vitale 2006: 20). Otro error frecuente es dar por supuesto que los migrantes buscan la reubicación permanente y la integración plena en la sociedad de acogida. Esto tiene por consecuencia centrar los debates sobre la necesidad de conferirles la nacionalidad, ignorando el gran conjunto de migrantes temporales que no buscan establecer lazos intensos o duraderos con los países de destino y tratando las injusticias que sufren este tipo de migrantes como si fuesen irrelevantes.

El segundo tipo de cuestiones hace referencia al marco de análisis en el que situar las injusticias: local, nacional, trasnacional o internacional. Las situaciones de injusticia no se constituyen tan sólo desde la intersección de las tres dimensiones señaladas más arriba, sino a través de la intersección de diversas escalas (Fraser 2010: 366369). Con esto quiere decirse que para comprender una injusticia debe atenderse al modo como se interrelacionan dinámicas estructurales pertenecientes a diferentes escalas. Si bien las instituciones pertenecientes al marco estatal son fundamentales para comprender la situación de cualquier colectivo, su análisis debe complementarse con la atención a las condiciones estructurales que provienen de otros niveles y la relación entre ellos. Los complejos procesos que constituyen la globalización han facilitado que los mecanismos de gobernanza del territorio "salten de escala" (Schiller 2010: 11). Tales mecanismos no deberían entenderse como operando de forma independiente en sus respectivos niveles u obedeciendo a una ordenada jerarquía, sino constituyéndose mutuamente y no necesariamente de forma correlativa. Sin duda las instituciones de cada Estado siguen siendo fundamentales para explicar lo que ocurre dentro de sus territorios, pero también es necesario considerar los condicionamientos que provienen tanto de lo global (Milanovic 2017: 265-269) como de lo local (Sassen 1994).

En tercer lugar, la migración es un proceso dinámico, por lo que se habrá de considerar las diferentes situaciones en las que los migrantes se encuentran en cada fase de su propio itinerario personal, sin limitarnos a considerar tan sólo algún momento puntual. Los elementos estructurales que condicionan su situación podrán variar según se consideren las circunstancias que les empujan a migrar, los condicionamientos de su desplazamiento o su vida en el país de destino, y aún incluso al retornar a sus países de origen y en otras posibles experiencias migratorias posteriores. No resulta aceptable reducir el análisis de las injusticias que sufren los migrantes a las condiciones que deben afrontar durante su tránsito, pues frecuentemente estas se encuentran interrelacionadas con lo que ocurre antes y después. Los mecanismos de acceso que diseñan los Estados incorporan también fases tempora- 
les, no simplemente una exclusión sine die o barreras territoriales, con la finalidad de lograr una "migración adaptada a demanda" (Mezzadra \& Neilson 2017: 157196). Atendiendo a los múltiples momentos que condicionan las circunstancias de los migrantes, se intenta trascender el modo como los filósofos normativos afrontan habitualmente las migraciones, esto es, discurriendo de manera prioritaria en torno a la legitimidad moral de las medidas restrictivas impuestas al libre movimiento de personas (Vitale 2006: 21).

Estos tres conjuntos de cuestiones esbozan un marco teórico desde el que analizar las injusticias que sufren los migrantes. No es más que una propuesta que se ofrece para intentar comprender situaciones concretas de injusticia, con el objetivo de erradicarlas. En modo alguno se intenta ofrecer un diseño ideal de una sociedad justa que diese la respuesta definitiva a los migrantes.

\section{Un ejemplo ficticio inspirado en casos reales}

EN ESTE APARTADO SE ANALIZARÁ un caso hipotético elaborado a partir de experiencias reales bastante típicas. Se pondrá así en práctica el marco de análisis planteado anteriormente. Se tomará como ejemplo una familia filipina de la minoría china que vive en Manila, cuyos miembros adultos trabajan en una sweatshop 1, subcontrata de una empresa transnacional de la moda, donde afrontan largos y duros turnos de trabajo recibiendo a cambio bajos salarios. Debido a esta situación, unida al conocimiento del programa japonés de reclutamiento de entertainers 2, sobre el cual circulan por el vecindario historias de positivas experiencias de personas que lo han seguido, esta familia toma la decisión de que el miembro femenino adulto, a quien llamaremos Darna, de 23 años, emprenda la vía migratoria. Tal decisión se hace, por supuesto, respetando su voluntad y en reconocimiento de sus habilidades para bailar y cantar. Se realiza también con la expectativa de que no sólo su esposo y sus dos hijos, sino también los padres de la migrante, que tendrán que asumir

\footnotetext{
${ }^{1}$ Las sweatshops son pequeños centros de elaboración de objetos de consumo, mayoritariamente textiles y calzado, situados en el más bajo nivel de la cadena de producción y distribución. Ubicados en países en vías de desarrollo, se nutren frecuentemente de una mano de obra feminizada, de baja cualificación y en condiciones de trabajo muy duras. Constituyen un caso clásico para ejemplificar las relaciones transnacionales y las responsabilidades difusas que pone en funcionamiento la economía globalizada. Sobre este fenómeno, véase Young (2011: 125-134).

2 A este estatus aspiran generalmente mujeres, procedentes mayoritariamente de Filipinas, que pretenden trabajar en bares en Japón acompańando y entreteniendo a hombres, sin que generalmente implique prostitución como frecuentemente se asume. Para acceder a este estatus, estas mujeres tienen que seguir complejos procesos de reclutamiento definidos por el gobierno japonés estando aún en Filipinas que implican a diversas empresas de ambos países.
} 
cuidados y responsabilidades sobre los hijos, se beneficien con las remesas. Esperan incluso poder hacer inversiones inmobiliarias locales o invertir en algún negocio en Filipinas.

Esta elección de migrar se produce impulsada, sin duda, por desfavorables condiciones de origen y un contexto estructural que les presenta la migración como una plausible alternativa a sus circunstancias. En estos casos debemos primero preguntarnos por las situaciones de injusticia que llevan a estas personas a tomar la siempre difícil decisión de migrar. Estas situaciones deben ser abordadas desde una perspectiva interseccional, considerando múltiples marcos y dimensiones sustanciales. A continuación, y sin pretensión de exhaustividad, se señalarán algunas de las intersecciones relevantes en el caso de Darna.

\subsection{Antes de la migración}

EN CUANTO A LA DIMENSIÓN DE RECONOCIMIENTO en nuestro caso se observa subordinación de estatus ligada a la pobreza y a la pertenencia a una etnia minoritaria, que puede obstaculizar la prosperidad de esta familia a través de, por ejemplo, su exclusión de puestos de trabajo mejor remunerados o la dificultad de obtener crédito para poner en marcha sus propios proyectos de inversión o empresariales. Esto puede ocurrir tanto en un marco local, por los prejuicios hacia los individuos de su grupo social, como en un marco trasnacional, porque la liberalización global del sector bancario ha provocado que el mercado de préstamos pase a estar dominado por bancos trasnacionales más proclives a financiar a otras corporaciones trasnacionales que a pequeños actores locales (Stiglitz 2002: 57).

Los aspectos relacionados con la distribución en el marco global han generado ya una extensa bibliografía ${ }^{3}$. Dada la complejidad de las relaciones económicas y la composición de las sociedades, sería conveniente evitar la perspectiva habitual de tomar a los países como totalidades homogéneas, frecuente en los análisis normativos sobre migraciones que basan sus argumentos en diferenciales macroeconómicos de renta per cápita y el derecho a la mejor calidad de vida que se da en los países más ricos. Los diversos grupos sociales estructuralmente vulnerables son sistemáticamente explotados dentro de las redes comerciales trasnacionales al recibir una parte desproporcionadamente reducida de los beneficios que produce su trabajo. Los acuerdos de la Organización Mundial del Comercio, unidos a la acelerada apertura

${ }^{3}$ Entre otras, son de interés las siguientes referencias: Harvey (2004), Milanovic (2017), Stiglitz (2002) y Sassen (2015). 
de los mercados impuestos por el Fondo Monetario Internacional a países en vías de desarrollo, han provocado la destrucción de la industria nacional y el dominio de las corporaciones trasnacionales regidas por intereses radicados más allá de las fronteras (Stiglitz 2002: 81-119). Las regulaciones nacionales sobre condiciones laborales tienden a flexibilizarse para atraer a inversores extranjeros y el recurso a subcontratas precarias para diluir las responsabilidades se convierte en una práctica habitual. Todo ello tiene como efecto las condiciones deplorables que Darna sufre en su puesto de trabajo y el bajo salario que recibe.

En la dimensión de distribución, sin embargo, no sólo nos encontramos con explotación. En la dinámica global de acumulación de capital es también fundamental la "acumulación por desposesión" o expropiación, que consiste en la "incautación de los bienes de las personas subyugadas (su trabajo, tierra, animales, herramientas, niños y cuerpos) y la canalización de esos activos confiscados en los circuitos de acumulación de capital" (Fraser 2018). Al desposeer a las personas de las tierras comunales, al acaparar las reservas de agua o al privatizar los recursos públicos, estos procesos de desposesión guiados por los intereses del capital global producen dramáticas expulsiones de las formas y lugares tradicionales de vida de un gran número de personas (Campillo 2019: 63-95; Sassen 2015a). Por otro lado, la precariedad económica causada por las nuevas condiciones globales repercute en otros tipos de condiciones locales y regionales, pues en una sociedad marcada por la fuerte subordinación de estatus según la clase económica, la mala redistribución económica tiene efectos sobre el reconocimiento, generando un círculo vicioso.

El marco nacional es indudablemente muy importante para las dimensiones de redistribución y reconocimiento. Es en este marco donde se aplican las normas relacionadas con las condiciones laborales, los derechos de los ciudadanos, la gestión empresarial o la lucha contra la corrupción. También aquí la dimensión política de la injusticia se manifiesta a través de la ineficacia de las instituciones nacionales, la falta de transparencia, la incapacidad de muchos ciudadanos de participar realmente en la elaboración de normas legales o en la existencia de clases privilegiadas. Pero como los críticos del nacionalismo metodológico vienen insistiendo, no podemos quedarnos sólo en este marco. En nuestro mundo en globalización, las limitaciones de los Estados son grandes, siendo aún mayores para los países en vías de desarrollo con escaso poder de negociación (Stiglitz 2006: 347-357).

Como se comentó en el primer apartado, el desajuste entre los mecanismos de participación política restringidos al marco nacional y los procesos globales hace surgir la injusticia del "desenmarque", la incapacidad de muchas personas de participar en la elaboración de normas globales que condicionan sus opciones de forma relevante (Fraser 2008: 43-64). Esta es una injusticia politica que surge al compar- 
timentar el mundo de forma que el interlocutor de las reivindicaciones de las personas sea a priori su propio Estado, cuando las razones de sus injusticias provienen de otros marcos que no dependen de este. Generalmente las personas sólo pueden interpelar a sus propios Estados, pero muchos de estos no tienen capacidad real de resolver las injusticias que sufren sus ciudadanos, pues son agentes con muy poco poder de negociación frente a otros Estados e incluso frente a las grandes corporaciones trasnacionales. La injusticia del "desenmarque" significa que suponer a priori que las injusticias que sufre una persona deben ser respondidas sólo en el marco nacional, constituye en sí mismo una injusticia. El ejemplo de la familia filipina que estamos considerando es claro al respecto. Sus injusticias provienen de diferentes marcos y, sin embargo, no participan en la formulación de las normas que se le imponen desde cada marco. De acuerdo con el principio democrático, deberían poder participar de algún modo en la gestión económica de la empresa en la que trabajan, en la formulación de los términos de la relación entre la subcontrata y la corporación trasnacional (Young 2000: 360-378), en la gobernanza global que genera las regulaciones a las que se encuentran sometidos (Innerarity 2012; Sassen 2003; Slaughter 2004; Zürn 2004) y en el control de las actividades que repercuten en su medio ambiente limitando sus posibilidades de vida (Sassen 2015b).

\subsection{Durante el desplazamiento}

EN SU PROCESO Migratorio, Darna sigue un canal diseñado explícitamente tanto por el Estado emisor como por el receptor. Y se trata de un diseńo que sitúa a las trabajadoras migrantes en una posición de extrema vulnerabilidad a la explotación laboral. El sistema oficial de reclutamiento de entertainers depende de diversos mediadores internacionales (representantes filipinos, agencias de promoción tanto filipinas como japonesas y propietarios de bares japoneses) que imponen enormes gastos y deudas a las migrantes relacionados con los procesos de selección y acreditación para la obtención de la visa. Frecuentemente estas mujeres tienen que emplear íntegramente el sueldo de sus primeros años de trabajo para pagar a sus mediadores (Salazar Parreñas 2011), los cuales se aseguran sus beneficios a través de restricciones de la movilidad de estas trabajadoras, reteniendo su pasaporte. Durante la duración de su contrato, generalmente de períodos de seis meses, no reciben salario alguno, pues este es administrado por sus empleadores y se dedica en sufragar sus gastos de manutención y las deudas relacionadas con la adquisición de la visa. La falta de recursos hace que las entertainers tengan que depender de los regalos que les hacen los clientes de los bares, reforzando así los patrones nacionales de subordi- 
nación de género. La distribución y el reconocimiento vuelven a estar estrechamente relacionados. Y todo esto sucede con la connivencia de los Estados, en especial el receptor, el autor y responsable último del diseño de este proceso migratorio.

Desde comienzos del siglo XXI el Department of State de Estados Unidos viene enmarcando estas migraciones como tráfico de personas desde la óptica de los derechos humanos. Sin embargo, a pesar de la efectividad que la retórica humanitarista pueda tener para otras injusticias, en este caso esta interpretación, al pretender ver la injusticia tan sólo fundamentada en las acciones inmorales de los mediadores, facilita el ocultamiento de los elementos estructurales determinantes y de las responsabilidades institucionales (Salazar Parreñas 2011: 5). Los procesos por los que pasa Darna no se explican como una relación entre traficantes y sus supuestas víctimas. Son los mismos Estados los que diseñan las condiciones estructurales que arrebatan a los migrantes el control sobre las condiciones de su migración, posibilitando su enorme vulnerabilidad.

Estructurar estas migraciones a través de múltiples mediadores obligatorios constituye una forma de injusticia de reconocimiento, pues este diseño responde a la representación de estas migrantes como sujetos a los que es preciso proteger, eternas menores de edad incapaces de negociar directamente por sí mismas los términos de su contratación, dispuestas a hacer actos que van en contra de su moralidad. Deben por ello ser "protegidas" por mediadores o por el Estado, encargados de salvaguardar paternalistamente su dignidad moral (Salazar Parreñas 2011: 40-56).

Por otro lado, el marco centrado en la retórica del tráfico de personas y en los derechos humanos se basa en la suposición de que estos derechos y sus mecanismos de aplicación son inherentemente buenos y libres de coste y serán por lo tanto bienvenidos si son ofrecidos. Frente a esta suposición, en su estudio con entertainers, Choo (2013) encontró que estas mujeres migrantes son generalmente reacias a recurrir a la protección de los derechos humanos reconocidos por los Estados de acogida frente a sus empleadores, y no apelan a ellos pese a que tienen pleno conocimiento de que estos derechos existen y de los procedimientos para reivindicarlos. Esto se debe a que recurrir a estos derechos, que el pensamiento mainstream considera inherentemente buenos y, por tanto, del todo irracional la actitud de estas mujeres, impone costes en la dimensión del reconocimiento que estas migrantes no están dispuestas a asumir. El régimen de los derechos humanos interpreta su situación como víctimas de tráfico de personas y víctimas de explotación sexual, posicionándolas como sujetos vulnerables en necesidad de protección. Categorizar a estas mujeres como víctimas indefensas conduce a la legitimación del Estado como protector, afectando negativamente su movilización y erosionando su estatus de igualdad (id.: 447-449). Este régimen de derechos humanos centrado en el tráfico de personas y 
la explotación sexual reforzaría sus posiciones subordinadas dentro de una jerarquía moral que afirma que el lugar adecuado del sexo es la institución romantizada del matrimonio, lo cual refuerza el estatus marginal de estas mujeres migrantes (id.: 453-456). Sin embargo, estas mujeres no quieren ser reconocidas como víctimas de tráfico de personas, pues ellas mismas no se ven como tales. No necesitan ser rescatadas, sino unas condiciones de migración que refuercen su autonomía y empoderamiento.

Estos problemas de reconocimiento erróneo encuentran correspondencia en el déficit de participación que las migrantes tienen en el diseño por parte del Estado japonés de las políticas de reclutamiento de entertainers. Al definir las condiciones y procesos de la migración, las agencias estatales responsables deberían estar abiertas a la participación y a la crítica de estas mujeres, que son sin duda quienes ven sus opciones de vida más coartadas por tales condiciones y procesos.

\subsection{Durante el asentamiento ${ }^{4}$}

EN LOS PAÍSES DE DESTINO, las injusticias que sufran los migrantes tendrán igualmente que analizarse atendiendo a las complejas intersecciones de las tres dimensiones y diversos marcos que venimos explorando. En cuanto a la dimensión de reconocimiento en el marco nacional, es muy probable que Darna sea víctima de diversos tipos de discriminación debido a los prejuicios raciales que perviven en al país de destino, Japón. Este tipo de injusticia frecuentemente surge de una legislación que coloca a las culturas minoritarias, a la cual Darna pertenece, en una posición de subordinación. Si los ciudadanos de grupos culturales minoritarios son vulnerables a la injusticia de reconocimiento, los migrantes sufren además el agravante de no tener reconocidos los plenos derechos políticos, de modo que la falta de estas herramientas reduce su capacidad de luchar contra tal injusticia. Su subordinación cultural se refuerza por su posición de migrante, crecientemente devaluada por un discurso lamentablemente en auge en las sociedades contemporáneas que asocia la migración con la criminalidad y la inseguridad (Velasco 2016: 39-44; Yamamoto 2007), lo cual alimenta el racismo, el desprecio y la violencia. Además, como ya se indicó en relación a las condiciones de su adquisición de la visa de entertainer

\footnotetext{
${ }^{4}$ A pesar de que nuestro análisis se detendrá en este punto, los momentos del experimento mental que se propone aquí pueden prolongarse. Darna no pretende el asentamiento permanente en Japón, por lo que volverá a su país de origen, retorno que, sin embargo, no constituirá una vuelta a su situación de partida. Independientemente de que su situación económica haya mejorado o no, a su retorno se enfrentará a circunstancias nuevas. Darna puede, como suele hacerse en estos casos, volver a establecer otro contrato temporal de entertainer, sumergiéndose en diversos ciclos de migración y retorno cada uno de los cuales será diferente al anterior.
} 
impuestas por Japón, sus condiciones de trabajo tenderán a reforzar los patrones de subordinación de género en su relación con sus clientes masculinos.

En relación a la dimensión de redistribución, Darna sufre explotación ya que grandes porciones de su salario son incautadas por los mediadores impuestos por el Estado japonés para regular su entrada en Japón. Este caso nos previene contra un presupuesto infundado frecuente en los análisis filosóficos de las injusticias que padecen los migrantes, este es, la asociación de la irregularidad con una mayor precariedad económica o laboral. Con frecuencia se asume que una trabajadora no documentada es más vulnerable a la explotación. En el caso de las entertainers lo contrario es lo más habitual. Este presupuesto tiene como efecto desviar la atención del modo como las mismas políticas públicas son las productoras de vulnerabilidad y explotación. En el caso de Darna los factores que posibilitan su explotación son precisamente los requisitos impuestos por el Estado japonés para la obtención de la visa de entertainer: los mediadores, los costes que conllevan deudas para la migrante, la residencia vinculada al contrato suscrito con sus mediadores, la incapacidad de las trabajadoras de negociar las condiciones de trabajo con los propietarios de los locales, etc. ${ }^{5}$. Las mujeres que dejan de tener un visado válido por romper su relación contractual con sus promotores pasan a estar capacitadas para negociar directamente con los propietarios de los locales sus condiciones de trabajo y evitan así mismo las comisiones de terceros. Por ello, disfrutan de mejores condiciones laborales y mayores salarios que las trabajadoras con visado legal (Salazar Parreñas 2011: 217-223), pero ello conlleva como contrapartida una mayor inseguridad legal y el riesgo de deportación.

En cuanto a la dimensión politica, es frecuente que los debates se centren en la injusticia que sufren los migrantes al ver dificultadas sus aspiraciones a lograr la residencia permanente y la plena integración en el Estado receptor. Con esto, es habitual que se tienda a privilegiar normativamente tanto a un grupo particular de migrantes -los que efectivamente organizan su migración con tal aspiración-, como la cuestión de la aceptabilidad moral de las condiciones que los Estados imponen para adquirir la residencia permanente o la nacionalidad (Benhabib 2005: 97-124; Carens 2013; Velasco 2016: 144-183). Según esta perspectiva, la adquisición de la ciudadanía parecería organizar teleológicamente las soluciones que normativamen-

\footnotetext{
5 Las entertainers, según los cauces legales avalados por el Estado japonés, tienen una relación contractual con su agencia de promoción filipina y su promotor japonés. Son estos los que distribuyen a sus trabajadoras en diferentes locales. Es decir, no tienen una relación contractual con los propietarios de los locales. Por ello no tienen capacidad de control sobre en entorno en el que realmente desarrollan su trabajo. Además, sólo las mantienen en el mismo local pocos meses, imponiéndoles una continua rotación que tiene por finalidad evitar la socialización en el entorno laboral, evitando que se asocien entre ellas y se sientan con fuerzas para protestar. Véase Choo (2016: 11).
} 
te se ofrecen a las injusticias políticas que sufren los migrantes. Incluso cuando los migrantes "temporales" se convierten en objeto de atención, la pregunta fundamental sigue siendo la misma: “ ¿cuándo los trabajadores admitidos de forma temporal adquieren el derecho moral a permanecer permanentemente?” (Carens 2013: 113). Pero esta forma de plantear la cuestión, tal vez válida para los migrantes que buscan un nuevo Estado en el que reconstruir su vida y la de su familia, sin duda una parte aún importante de los fenómenos migratorios actuales, es enormemente inapropiada en otros muchos casos, como en el de nuestros ejemplo ${ }^{6}$. Lo que aquí se busca es precisamente un marco de análisis que no privilegie normativamente de partida ningún tipo particular de migración, sino que se abra a su complejidad. La cuestión es si estas personas pueden legítimamente reclamar formas de participación política aún sin aspirar a asentarse en el Estado receptor ni a alcanzar el estatus político de ciudadano, y cuáles son estas formas, que para algunos casos serían tan suficientes y legítimas como la adquisición de la ciudadanía en otros. Cuestión que sin duda también preocupa a los autores citados más arriba a pesar de su prioritaria atención a la cuestión de la ciudadanía y del derecho a residir permanentemente.

El sentido de la migración de Darna es mejorar las condiciones de vida de su familia en Filipinas, ahorrar dinero para invertir allí en propiedades inmobiliarias o en establecer algún negocio. Su interés por integrarse en Japón en mínimo y esto no nos debería llevar a presuponer que sus injusticias políticas sean irrelevantes porque estas deberían medirse sólo en relación al objetivo final de adquirir la ciudadanía. Aún sin pretender adquirir este estatus ni el derecho de voto, deberían tener voz en los procesos decisorios que definen sus condiciones laborales y de movilidad poniéndolas a merced de mediadores que las hacen vulnerables a la explotación y a la subordinación, así como en sus condiciones locales de vida. Tampoco debe presuponerse que todas las respuestas a las injusticias políticas deben darse en el marco nacional. En este sentido, ante la despreocupación que el gobierno nacional adopta ante las condiciones de los migrantes, son las administraciones locales japonesas las que muestran una preocupación creciente por ellas, habilitando canales de participación de los migrantes que no dependen del derecho de voto negado por el Estado (Tsuda 2008). Los procesos de globalización están provocando un desacoplamiento de los conceptos de ciudadanía y Estado nacional, que da lugar a diferentes espacios y prácticas políticas que rompen con la jerarquía de escalas centrada en el Estado-nación (Sassen 2010: 349-403). Entre estos espacios emergentes generadores de nuevos agentes y prácticas políticas destaca la ciudad. En las

\footnotetext{
${ }^{6}$ Esto puede que no sea ni siquiera válido para todos los casos de residentes permanentes, como el ejemplo de los coreanos zainichi en Japón muestra, quienes a pesar de haber residido en Japón desde el final de la Segunda Guerra Mundial, se oponen activamente a la adquisición de la ciudadanía japonesa. Véase Chung (2006).
} 
ciudades se torna manifiesta la presencia de los migrantes, una realidad que no cabe negar, y las autoridades locales se ven obligados a lidiar con sus problemas y atender sus reivindicaciones ofreciéndoles servicios y derechos negados por el Estado.

Finalmente, no podemos pasar por alto el aspecto trasnacional de las reivindicaciones políticas y el empoderamiento obrado a través de la migración. En su análisis sobre mujeres migrantes en Japón, Ruri Ito (2005) observó que la mayoría de las organizaciones que formaban estaba destinada a la ayuda mutua y asesoramiento, también tenían bastante presencia las organizaciones que realizaban actividades para mantener sus culturas y mejorar su reconocimiento en el país de acogida. Parece que mientras duraba su experiencia migrante, interpelar al Estado de acogida para mejorar sus derechos no forma parte de sus prioridades. El mayor interés de estas migrantes sería mejorar su capacitación profesional y habilidades, y especialmente buscan su empoderamiento no en su país de acogida, sino en su país de origen a su vuelta (Ruri 2005: 65). Sólo si nos hacemos cargo del trasnacionalismo politico, múltiple y dinámico de estas migraciones (Bauböck 2010; Velasco 2016: 98-143) y superamos el carácter reductivo de esa literatura que trata como objeto privilegiado de estudio la incorporación de los migrantes permanentes en la sociedad política de acogida, seremos capaces de observar las múltiples formas de la dimensión política de la migración.

\section{Observaciones finales}

EN PRIMER LUGAR, el análisis que se ha realizado insiste en que no existe la injusticia de los migrantes, sino una red compleja de intersección de múltiples injusticias que se desarrollan según diferentes dimensiones y marcos sólo separables analíticamente. El caso de Darna nos ha permitido mostrar el error en el que caen muchos planteamientos normativos al pretender iluminar grandes recetas o criterios supuestamente válidos para evaluar la situación de todo migrante porque se supone que con ellos se señala la injusticia fundamental que afrontan. En especial se debe evitar la reducción habitual en los debates actuales de la cuestión migratoria a un asunto de control de fronteras o de distribución de la nacionalidad. A pesar de que es frecuente pretender resolver de un golpe la injusticia que sufren los migrantes argumentando en abstracto en contra de los impedimentos que las fronteras estatales oponen al libre movimiento, esta no era una perspectiva prometedora sobre la situación de Darna. Su condición de migrante está arraigada en injusticias previas al movimiento y ella, además, como tantos otros en nuestro tiempo, sigue un canal abierto y estructurado por el gobierno japonés. El hecho de que sus opciones estén 
estructuradas no es en sí mismo una injusticia que típicamente sufran los migrantes. Que nuestras opciones estén estructuradas es una condición constituyente y necesaria de la vida social que todos sufrimos en cada una de nuestras acciones. La respuesta de la teoría de la justicia a esto no puede ser aspirar a una supuesta libertad total e ingenua de movimiento y de elección, carente de cualquier fundamento de ontología social, sino descender a las condiciones de esta estructuración y estudiar el modo complejo como esta se realiza, para indagar si coloca a algunas clases sociales en situación de explotación, subordinación o dominación con respecto a otras clases. Por otro lado, también se ha visto que la cuestión de adquirir la nacionalidad o la residencia permanente en Japón es de poca relevancia para Darna. La literatura que se centra en esto como la clave de las injusticias de los migrantes es ciega ante un inmenso grupo de migrantes.

En segundo lugar, la exposición de las injusticias que podría sufrir Darna ha sido tan sólo una posible ejemplificación de cómo podrían ser abordadas estas cuestiones. No pretendía ser exhaustiva, no simplemente por falta de espacio, sino porque tal pretensión se considera inalcanzable. Pretender exponer la injusticia esencial de los migrantes o las injusticias completas que sufren, caería en el paternalismo de reflexiones de sillón. Los elementos estructurales que tomamos como objeto de crítica y los diversos marcos y dimensiones desde los que se analizan son una cuestión de perspectiva, algunas de las cuales serán más críticas o explicativas que otras, según el momento y el tipo de interrelaciones sociales. Las relaciones sociales que tomamos como objeto de análisis y las injusticias que resaltamos dependen de nuestras intenciones y valores, de los problemas sociales ante los que nuestro momento histórico es más sensible, de los discursos justificativos hegemónicos o de la cambiante realidad de nuestras instituciones. Debemos, por todo ello, asumir la finitud de nuestros análisis y abrazar una continua renovación de la crítica. La lucha contra las injusticias es una labor abierta y siempre en proceso de reinterpretación.

No podemos terminar sin hacer notar que nuestra sociedad global, ante la compleja red de relaciones que generan las injusticias que sufren los migrantes, adolece de una carencia que reclama solución. Pues a pesar de que en muchos otros ámbitos nos hemos dotado de un sistema de gobernanza para afrontar problemas globales, es urgente llenar el vacío que aún existe en relación a la migración internacional para poder actuar de forma coordinada y debatir sobre las políticas que podrían estructurar de forma más justa los flujos migratorios. 


\section{Referencias Bibliográficas}

Arcos Ramírez, Federico. 2008. Ética y pobreza mundial: fundamento y límites de una respuesta centrada en los deberes de humanidad. Anuario de filosofía del Derecho (XXV): 149-178.

Bauböck, Rainer. 2010. Hacia una teoría política del transnacionalismo de los emigrantes. En Ciudadanía sin nación, eds. L. J. Ariza \& I. Barbero González. Bogotá: Siglo del hombre.

Benhabib, Seyla. 2005. Los derechos de los otros. Barcelona: Gedisa.

Blake, Michael. 2014. The right to exclude. Critical Review of International Social and Political Philosophy 17 (5): 521-537.

Campillo, Antonio. 2019. Un lugar en el mundo. La justicia espacial y el derecho a la ciudad. Madrid: Catarata.

Caney, Simon. 2006. Justice Beyond Borders. A Global Political Theory. Oxford: Oxford University Press.

Carens, Joseph H. 2013. The Ethics of Immigration. Oxford: Oxford University Press.

Choo, Hae Yeon. 2013. The Cost of Rights: Migrant Women, Feminist Advocacy, and Gendered Morality in South Korea. Gender and Society 27 (4): 445-568.

Choo, Hae Yeon. 2016. In the Shadow of Working Men: Gendered Labor and Migrant Rights in South Korea. Qualitative Sociology, 1-21.

Chung, Erin A. 2006. Immigration and Citizenship in Japan. Cambridge: Cambridge University Press.

Forst, Rainer. 2014. Justificación y crítica. Madrid: Katz.

Fraser, Nancy. 2006. La justicia social en la era de la política de la identidad: Redistribución, reconocimiento y participación. En ¿Redistribución o reconocimiento?, eds. N. Fraser \& A. Honneth, 17-88. Madrid: Morata.

Fraser, Nancy. 2008. Escalas de justicia. Barcelona: Herder.

Fraser, Nancy. 2010. Injustice at Intersecting Scales: on "Social Exclusion" and the "Global Poor". European Journal of Social Theory 13 (3): 363-371.

Fraser, Nancy. 2018. ¿¿Podemos entender el populismo sin llamarlo fascista? Entrevista. Consultado el 23/07/2018 http://www.sinpermiso.info/textos/podemos-entender-el-populismo-sin-llamarlo-fascista-entrevista 
Harvey, David. 2004. The 'new' imperialism: accumulation by dispossession. Socialist register 40: 63-87.

Innerarity, Daniel. 2012. La gobernanza global, de la soberanía a la responsabilidad. Revista CIDOB d'Afers Internacionals (100): 11-23.

Mezzadra, Sandro, \& Neilson, Brett. 2017. La frontera como método. Madrid: Traficantes de sueños.

Milanovic, Branko. 2017. Desigualdad mundial: un enfoque para la era de la globalización. México: FCE.

Miller, David. 2008. National responsibility and global justice. Critical Review of International Social and Political Philosophy 11 (4): 383-399.

Miller, David. 2016. Strangers in our Midst. Cambridge, Mass.: Harvard University Press.

Miller, Richard W. 1998. Cosmopolitan Respect and Patriotic Concern. Philosophy \& Public Affairs 27 (3): 202-224.

Rawls, John. 2001. El derecho de gentes y "Una revisión de la idea de razón públi$c a$ ". Barcelona: Paidós.

Rawls, John. 2014. Teoría de la Justicia. México: FCE.

Risse, Mathias. 2016. On the Significance of Membership in Approaches to Global Justice. Journal of Applied Philosophy 33 (4): 443-449.

Ruri, Ito. 2005. Crafting Migrant Women's Citizenship in Japan: Taking "Family" as a Vantage Point. International Journal of Japanese Sociology (14): 52-69.

Sager, Alex. 2016. Methodological Nationalism, Migration and Political Theory. Political Studies 64 (1): 42-59. doi: https://doi.org/10.1111/1467-9248.12167

Salazar Parreñas, Rhacel. 2011. Illicit Flirtations. Labor, Migration, and Sex Trafficking in Tokyo. Stanford: Stanford University Press.

Sangiovanni, Andrea. 2013. On the Relation Between Moral and Distributive Equality. En Cosmopolitanism versus Non-Cosmopolitanism, ed. G. Brock, 55-74. Oxford: Oxford University Press.

Sassen, Saskia. 1994. Cities in a World Economy. Thousand Oaks: Pine Forge Press.

Sassen, Saskia. 2003. The Participation of States and Citizens in Global Governance. Indiana Journal of Global Legal Studies 10 (1): 5-28. doi: https://doi. org/10.2979/gls.2003.10.1.5 
Sassen, Saskia. 2010. Territorio, autoridad y derechos. Buenos Aires: Katz.

Sassen, Saskia. 2015a. Expulsiones. Brutalidad y complejidad en la economía global. Buenos Aires: Katz.

Sassen, Saskia. 2015b. Massive loss of habitat triggers new array of migrations. trumanfactor. Obtenido de http://trumanfactor.com website: http://trumanfactor.com/2015/saskia-sassen-interview-2-15136.html

Schiller, Nina Glick. 2010. A Global perspective on Transnational Migration: Theorizing Migration without Methodological Nationalism. En Diaspora and Transnationalism, eds. R. Bauböck \& T. Faist, 109-129. Amsterdam: Amsterdam University Press.

Slaughter, Anne-Marie. 2004. Disaggregated Sovereignty: Towards the Public Accountability of Global Govermente Networks. Goverment and Opposition 39 (2): 159-190.

Stiglitz, Joseph E. 2002. El malestar en la globalización. Madrid: Taurus.

Stiglitz, Joseph E. 2006. Cómo hacer que funcione la globalización. Madrid: Taurus.

Tsuda, Takeyuki. 2008. Local Citizenship and Foreign Workers in Japan. The Asia-Pacific Journal. Japan Focus 6 (5).

Velasco, Juan Carlos. 2016. El azar de las fronteras. Politicas migratorias, ciudadanía y justicia. México: FCE.

Vitale, Ermanno. 2006. Ius migrandi. Santa Cruz de Tenerife: Melusina.

Yamamoto, Ryoko. 2007. Migrant-support NGOs and the Challenge to the Discourse on Foreign Criminality in Japan. The Asia-Pacific Journal. Japan Focus 5 (9).

Young, Iris Marion. 2000. La justicia y la politica de la diferencia. Madrid: Cátedra.

Young, Iris Marion. 2011. Responsabilidad por la justicia. Madrid: Morata.

Zürn, Michael. 2004. Global Gobernance and Legitimacy Problems. Goverment and Opposition 39 (2): 260-287.

DOI: http://dx.doi.org/10.15366/bp.2020.23.006

Bajo Palabra. II Época. No23. Pgs: 163-186 
